CORRECTION OPEN

\title{
Correction: Long-term bone and lung consequences associated with hospital-acquired severe acute respiratory syndrome: a 15-year follow-up from a prospective cohort study
}

Peixun Zhang, Jia Li, Huixin Liu, Na Han, Jiabao Ju, Yuhui Kou, Lei Chen, Mengxi Jiang, Feng Pan, Yali Zheng, Zhancheng Gao and Baoguo Jiang

Bone Research (2020)8:34

; https://doi.org/10.1038/s41413-020-00113-1

Correction to: Bone Research https://doi.org/10.1038/s41413-0200084-5, published online 14 February 2020

During a re-read of our article ${ }^{1}$ previously published in Bone Research, we regrettably found a omitting in the acknowledgement section relating to the supporting foundation.

That work was also supported by the Key Laboratory of Trauma \& Neural Regeneration (Peking University), Chinese Ministry of Education (Number: BMU2019XY007-01); and Major R\&D Program of Chinese National Ministry of Science and Technology (2018YFB1105504).

\section{ACKNOWLEDGEMENTS}

We thank all the SARS patients for their commitment to this study and all other staff members for their contributions, especially the Department of Personnel Division of Peking University People's Hospital. We thank Clare Cox, Ph.D., from Liwen Bianji, Edanz Editing China (www.liwenbianji.cn/ac) for editing the English text of a draft of this manuscript. This work was supported by Innovation Team of the Ministry of Education (IRT1601), the National Key Research and Development Programme of China (2016YFC0903800), the National Natural Science Foundation (31771322, 31571235), Fostering Young Scholars of Peking University Health Science Center (BMU2017PY013), Beijing Science \& Technology New Star Cross Project (201819), the
Key Laboratory of Trauma \& Neural Regeneration (Peking University), Chinese Ministry of Education (Number: BMU2019XY007-01); and Major R\&D Program of Chinese National Ministry of Science and Technology (2018YFB1105504).

\section{REFERENCE}

1. Zhang, P. et al. Long-term bone and lung consequences associated with hospitalacquired severe acute respiratory syndrome: a 15-year follow-up from a prospective cohort study. Bone Res. 8, 8 (2020).

\begin{abstract}
cC) (i) Open Access This article is licensed under a Creative Commons adaptation, distribution and reproduction in any medium or format, as long as you give appropriate credit to the original author(s) and the source, provide a link to the Creative Commons license, and indicate if changes were made. The images or other third party material in this article are included in the article's Creative Commons license, unless indicated otherwise in a credit line to the material. If material is not included in the article's Creative Commons license and your intended use is not permitted by statutory regulation or exceeds the permitted use, you will need to obtain permission directly from the copyright holder. To view a copy of this license, visit http://creativecommons. org/licenses/by/4.0/.
\end{abstract}

(c) The Author(s) 2020 